\title{
EVALUATING THE IMMEDIATE EFFECTS OF DEEP PRESSURE ON CHILDREN DEVELOPMENTAL COORDINATION DISORDER: DEMONSTRATING INDIVIDUAL DIFFERENCES
}

\author{
GANAPATHY SANKAR $\mathrm{U}^{1}$, MONISHA $\mathrm{R}^{1 *}$, CHRISTOPHER AMALRAJ VALLABA DOSS ${ }^{2}$, PALANIVEL RM ${ }^{3}$
}

${ }^{1}$ Ph.D Scholar, SRM College of Occupational Therapy, SRM Institute of Science and Technology, Chennai, Tamil Nadu, India. ${ }^{2}$ College of Medicine, Imam Abdulrahman Bin Faisal University, Dammam 31441, Saudi Arabia. ${ }^{3}$ Deanship of Quality and Academic Accreditation, Imam Abdulrahman Bin Faisal University, Dammam 31441, Saudi Arabia. Email: dreamsfuture000@gmail.com

Received: 14 December 2019, Revised and Accepted: 09 January 2020

ABSTRACT

Objective: However, every occupational therapist used deep pressure for treating children with developmental coordination disorder (DCD). It has been used widely in the therapy aspect, but there is limited research evaluating the immediate effects of deep pressure. The current study aims to evaluate the immediate effects of deep pressure on children with DCD.

Methodology: Pre-test and post-test design was employed; mood and behavior were assessed for 20 children with DCD before and after deep pressure sessions.

Results: Five children responded with positive result on all the domains following deep pressure. Four showed positive result on three out of five domains. Sufficient information was available from eight participants. Three showed beneficial results statistically. A non-parametric technique (Tau-U) was used for the analysis.

Conclusion: Deep pressure has high relevance to clinical practice and appears to be of immediate benefit to this population with DCD.

Keywords: Developmental coordination disorder, Deep pressure, Primary school children, Immediate effects.

(C) 2020 The Authors. Published by Innovare Academic Sciences Pvt Ltd. This is an open access article under the CC BY license (http://creativecommons. org/licenses/by/4. 0/) DOI: http://dx.doi.org/10.22159/ajpcr.2020.v13i3.36625

\section{INTRODUCTION}

Developmental coordination disorder (DCD) is overlooked by clinical practitioners. There is extensive evidence on how the child with DCD faces difficulties to organize activities of daily living (ADL); they have trouble in planning and sequencing any motor task in an unfamiliar as well as the familiar environment. Even the simple motor task, for example, buttoning a shirt, which is easy, acquired skill by other children without any effort. However, the same activity needs the highest effort and it is considered to be a very complicated skill for the child with DCD [1]

This motor coordination defect troubled the children both in school and at home. In 1925, these children were referred to as debility motrice (motorically deficient). Clumsiness is their major feature and this terminology has been used often by Orton to describe a group of children with motor coordination deficit. In 1940, their symptoms were collectively defined and the clumsy side is described as awkward in movements, poor at games, hopeless in dancing and gymnastics, a bad writer, and defective in concentration. He is inattentive, cannot sit still, leaves his shoelaces untied, do buttons wrongly, bumps into furniture, breaks glassware, slips off his chair, kicks his legs against the desk, and perhaps reads badly [2].

There were a huge number of unsolved mystery exist in the past. By 1994, the American Psychiatric Association described DCD as a chronic and usually a permanent condition found in children and is characterized by motor impairment that interferes with the child's ADL and academic achievement. DCD is not diagnosed before the age of 5 years due to variation in the age at which children develop their motor skills (Sankar and Monisha). Children must rule out the possibility of a physical medical condition or learning disability. The prevalence of DCD is high among school-going children and research found that there is at least one child has DCD problem in every classroom [3].

Increased blood pressure, heart rate, and respiratory rate were the physiological indicators of stress, following the application of deep pressure. Another effective and most widely used type of Sensory-based interventions (SBI) is brushing. However, Ganapathy et al. conducted a study titled, "Examining the use of deep touch pressure to improve the educational performance of students with disabilities: A metaanalysis," in 2016. Monisha [4,5] concluded that Wilbarger brushing had no effect. To manage behavioral problems, SBI such as massage or brushing can be used effectively, which has been proved Yunus et al., in 2015. However, there is much debate on how to conceptualize the SBI intervention on time and the response provided by each child varies, thus evidence behind SBI intervention is low.

\section{METHODOLOGY}

To evaluate the effects of deep pressure on children, a pretest-posttest design was employed. The study was approved after proposal presented in SRM College of Occupational Therapy (SRMIST): Minute number 800 dated November 2018. The procedure includes requesting consent from the parents of each child. The study took place in a therapy center for children with DCD. Ten children were included in the study after they were diagnosed as DCD based on the MABC test result. Symptoms of the child, which were thought to indicate a need for deep pressure, included tapping feet and hands, banging head, jumping, and running over the room. The age of the child included is from 5 years to 10 years. Table 1 shows further details of the child. Visual analog scales (VAS) are $10 \mathrm{~cm}$ horizontal or vertical lines which include "not at all" at one end and "very" at another end. VAS is used most commonly to assess the pain status and measuring mood status and activity of children in school. To use the scale, training had been given to the therapist by the primary researcher. For the purposes of measuring mood, VAS includes two anchor points for the calmness "not at all calm" and "very calm." Five domains were assessed in this study - calmness, participation in activities, responsiveness to command or stimulus from the environment, happiness, and communicativeness. The VAS is used to assess the outcome and it is simple to use, yet provides the indication of short-term effects of deep pressure. If the child or the parent does not 
want to continue with the further sessions of deep pressure, they were allowed to discontinue from the study at any time.

Deep pressure techniques used in the current study are brushing, massage, and squeezing. They were delivered in a distraction-free environment by an occupational therapist, the primary researcher Dr. U. Ganapathy Sankar certified in sensory integration therapy. Deep pressure sessions were delivered 3 times daily during their school hours. Sessions were scheduled between 5 and $15 \mathrm{~min}$. The deep pressure was delivered over a period of 3 months on weekdays when the young people were in school. A therapist who administered the deep pressure rated the effects of deep pressure therapy before the session and again 30 min after the session.

\section{RESULTS}

Data will be collected for 20 young people for whom a total of 15 sessions were evaluated. Eight children do not have sufficient details for reliable statistical analysis. The statistical analysis used in the current study is the Tau-U statistic which analyzes the difference in the data range. It is a non-parametric statistical technique. The analysis reported is before and after deep pressure. Table 2 describes the means and standard deviations of the five domains before and after deep pressure sessions. When all the sessions were examined following deep pressure therapy, children with DCD showed statistical significance. Five children responded with positive results on all the domains following deep pressure. Four showed positive results on three out of five domains. Sufficient information was available from eight participants. Three showed beneficial results statistically.

\section{DISCUSSION}

Deep pressure showed positive effect for the majority of children with DCD in this study [6-8]. However, the effects were not similar among the children participated in this study. The effects of deep pressure are not uniform among children's with DCD and it is made easy to understand that individual differences exist among these children and it needs to be taken into account while planning and delivering treatment. Table 1

Table 1: Participants details

\begin{tabular}{|c|c|c|c|c|c|c|c|c|}
\hline S. No. & Name & Age & Cognitive & $\begin{array}{l}\text { Expressive } \\
\text { language }\end{array}$ & $\begin{array}{l}\text { Fine } \\
\text { motor }\end{array}$ & $\begin{array}{l}\text { Gross } \\
\text { motor }\end{array}$ & VMI & Reason for deep pressure \\
\hline 1. & Tarun & 5 & 35 & 25 & 30 & 29 & 20 & Hitting head against other people \\
\hline 2. & Kaviya & 5 & 25 & 20 & 20 & 23 & 15 & Tapping hands and feet over the floor and wall \\
\hline 3. & Vasanth & 5 & $<12$ & 11 & 15 & 20 & 15 & Hiding inside the room, extreme sensitivity to light and sound \\
\hline 4. & Tamil selvi & 5 & 20 & 25 & 20 & 15 & 15 & Jumping over objects and hitting \\
\hline 5. & Kartick & 5 & $<12$ & $<12$ & 20 & 15 & 15 & Hitting over the wall \\
\hline 6. & Mani & 6 & 11 & 15 & 25 & 18 & 25 & Slapping his face \\
\hline 8. & Saravanan & 7 & 22 & 25 & 20 & 22 & 20 & Difficulty in playing outside (sensitivity to light) \\
\hline 9. & Kumar & 7 & 30 & 30 & 27 & 23 & 20 & Compress himself \\
\hline 10. & Deepika & 8 & 20 & 20 & 20 & 23 & 25 & Avoids peer group play in green land, sensitive to light and sound \\
\hline 11. & Manisha & 8 & 12 & 24 & 12 & $<12$ & 30 & Hits over objects while walking \\
\hline 12. & Kavitha & 8 & 15 & 11 & 12 & 12 & 12 & Runs and bumps over objects \\
\hline 13. & Gomathy & 8 & 23 & 25 & 26 & 22 & 22 & Throws objects over persons \\
\hline 14. & Priya & 8 & $<12$ & $<12$ & $<12$ & $<12$ & $<12$ & Slaps her own body with objects \\
\hline 15. & Elizabeth & 9 & 25 & 22 & 22 & 22 & 22 & Engaged in self harming activities \\
\hline 17. & Balaji & 9 & 35 & 32 & 22 & 22 & 22 & Sensitivity to sound \\
\hline 18. & Boobalan & 10 & $<12$ & 12 & 20 & 21 & 22 & Lacks attention \\
\hline 19. & Riteesh & 10 & 34 & 32 & 32 & 32 & 32 & Frequently hits over wall and fall \\
\hline 20. & Madan & 10 & 32 & 22 & 21 & 21 & 23 & Self-destructive behavior \\
\hline
\end{tabular}

VMI: Visual motor integration

Table 2: Mean scores before and after deep pressure

\begin{tabular}{|c|c|c|c|c|c|c|c|c|c|c|c|c|}
\hline \multirow[t]{2}{*}{ S. No. } & \multirow[t]{2}{*}{ Participants } & \multicolumn{5}{|c|}{ Domain - pre-test } & \multicolumn{5}{|c|}{ Post-test } & \multirow[t]{2}{*}{$\mathrm{Z}$ value } \\
\hline & & $\mathbf{A}$ & B & $\mathrm{C}$ & D & $\mathbf{E}$ & $\mathbf{A}$ & B & C & D & $\mathbf{E}$ & \\
\hline 1. & Tarun & 4.45 & 3.43 & 4.41 & 5.42 & 3.22 & 6.54 & 4.44 & 5.44 & 5.99 & 4.21 & 5.66 \\
\hline 2. & Kaviya & 5.32 & 5.22 & 5.11 & 5.87 & 5.32 & 6.34 & 6.32 & 6.45 & 7.32 & 7.00 & 6.32 \\
\hline 3. & Vasanth & 4.34 & 4.34 & 4.54 & 4.65 & 4.77 & 5.67 & 5.76 & 5.88 & 5.87 & 5.99 & 6.45 \\
\hline 4. & Tamil selvi & 7.54 & 7.21 & 6.54 & 6.21 & 6.21 & 8.90 & 8.88 & 6.98 & 7.86 & 7.54 & 9.00 \\
\hline 5. & Kartick & 3.23 & 3.45 & 3.00 & 3.98 & 3.22 & 5.34 & 4.34 & 5.34 & 5.34 & 5.78 & 6.98 \\
\hline 6. & Mani & 4.44 & 4.34 & 4.09 & 4.98 & 4.34 & 5.32 & 5.34 & 5.78 & 5.23 & 5.78 & 6.987 \\
\hline 7. & Deepak & 5.24 & 5.21 & 5.09 & 5.98 & 5.77 & 6.34 & 6.21 & 6.34 & 6.45 & 6.24 & 7.12 \\
\hline 8. & Saravanan & 4.32 & 4.32 & 4.99 & 4.12 & 4.23 & 5.43 & 5.12 & 5.34 & 6.23 & 5.94 & 6.98 \\
\hline 9. & Kumar & 5.43 & 5.67 & 5.89 & 5.23 & 5.76 & 6.44 & 6.23 & 6.65 & 6.34 & 698 & 7.98 \\
\hline 10. & Deepika & 2.34 & 2.34 & 2.54 & 2.11 & 2.00 & 5.33 & 3.00 & 5.45 & 5.98 & 5.99 & 6.98 \\
\hline 11. & Manisha & 4.44 & 4.76 & 4.34 & 4.54 & 4.21 & 4.1 & 4.65 & 4.76 & 4.66 & 4.65 & -3.333 \\
\hline 12. & Kavitha & 5.34 & 5.90 & 5.00 & 5.90 & 5.33 & 6.2 & 6.13 & 6.34 & 6.55 & 6.56 & 7.00 \\
\hline 13. & Gomathy & 6.32 & 6.77 & 6.89 & 6.23 & 6.22 & 8.5 & 8.98 & 8.77 & 8.45 & 8.77 & 9.009 \\
\hline 14. & Priya & 7.43 & 7.89 & 7.45 & 7.23 & 7.12 & 7.33 & 7.34 & 7.5 & 7.44 & 7.45 & -4.445 \\
\hline 15. & Elizabeth & 8.45 & 8.34 & 8.35 & 8.90 & 8.09 & 9.99 & 9.45 & 9.7 & 9.45 & 9.34 & 9.00 \\
\hline 17. & Balaji & 5.67 & 5.46 & 5.67 & 5.34 & 5.32 & 6.45 & 6.34 & 6.4 & 6.45 & 6.45 & 7.67 \\
\hline 18. & Boobalan & 5.87 & 5.67 & 5.43 & 5.23 & 5.23 & 6.44 & 6.56 & 6.5 & 6.55 & 6.45 & 7.56 \\
\hline 19. & Riteesh & 7.45 & 7.65 & 7.98 & 7.00 & 7.23 & 8.56 & 8.23 & 8.4 & 8.45 & 8.98 & 9.56 \\
\hline 20. & Madan & 7.56 & 7.34 & 7.65 & 7.09 & 7.12 & 6.4 & 7.5 & 7.3 & 7.6 & 7.7 & -5.55 \\
\hline
\end{tabular}


shows the participants' details and the therapist reported that the behavior and mood of the children were improved in the course of the study. The variability of responses among children with DCD to deep pressure therapy may be of importance clinically. Of the 20 participants, four (Tarun, Kavya, Vasanth, and Tamil selvi) showed a wide-ranging improvement in the behaviors, for which their parents reasoned out to initiate treatment program.

Kumar, Mythile, Balaji, and Boopalan responses to deep pressure were less and they did not show any improvement in the behavior, they have quoted at the baseline. Madan, Riteesh, Elizabeth, and Priya showed improvements and they were calm and turned out to get engaged in activities. Surprisingly, Gomathy started to communicate effectively with peer group children following sessions of deep pressure, suggesting that, for some children with DCD, peer group interaction may be enabled. Neither Priya nor Manisha seemed to benefit from deep pressure.

Ganapathy Sankar and Saritha found that the prevalence of DCD at Kattankulathur village in Tamil Nadu was $1.37 \%$ by the year 2011 . The prevalence of DCD in the USA is $5-8 \%, 5.7 \%$ in Greek, $1.8 \%$ in the United Kingdom, 5-9\% in Canada, and 6\% in worldwide [7-10]. Early identification of DCD is necessary to the prevalence of DCD at Kattankulathur. About $50 \%$ presents poor academic performance, play, and ADL skills in children. A sensation which has been indulged when a child is stroked (central to peripheral), squeezed, hugged, or even held strongly is deep pressure $[9,10]$.

Worldwide, occupational therapists were using this technique, somewhere in their therapy part as well as in their assessments. It is also used in children with DCD [11] and this deep pressure has benefits of enhancing performance in school. It is based on sensory integration. Researcher T. Grandin and M. Scariano from the USA in the year 1986 devised an equipment hug machine and examined the effects of pressure sensation delivered by this machine over individuals, the researcher self-tested the equipment they devised and found the hug machine relived the stress and it gives enough pressure to stimulate all the receptors. This hug machine was developed based on the idea delivered by Ayres in the 1960s and 1970s [11].

The idea of using deep pressure was used later on. Other types of deep pressure therapy include therapeutic brushing which is simple and most widely used by therapists. Much debate lies with the evidence underlying sensory integration therapy. However, insufficient evidence is reported by the researchers for the sensory integration therapy in educational use. Careful evaluation part is needed to use sensory integration therapy for educational and therapeutic purpose. Since 2015, J. Case-Smith and Weaver made a distinction between the use of sensory integration therapy and sensory-based interventions. A systematic review published in 2015 had explored the sensory processing interventions [12].

Based on the findings of Case-Smith et al., it has been concluded that adult-directed use of deep pressure therapy can be used as a sensory modality and when the sensory stimulus is activate over the child, it appears to enhance the child's performance in school and it is expected to control the symptoms of DCD [12]. Thus, deep pressure can be delivered by caregivers and it falls under the category of SBI. It fails when it is applied as sensory integration therapy. However, it is applied for all children with DCD, the heterogeneity of responses makes evidence for SBIs such as deep pressure is less convincing.

For instance, many forms of sensory-based intervention were not tested on children with DCD. Case-Smith et al. identified in his systematic review that brushing and joint compression were used on two studies and seven studies used weighted vests, two studies used therapy balls, and four studies used multiple methods including deep pressure. Chen et al., in his research study "Physiological effects of deep touch pressure on anxiety alleviation: The weighted blanket approach," found that weighted blanket approach reduced anxiety in 12 typically developing children. However, these signs of reduced anxiety were measured physiologically but not behaviorally [12].

It was unclear why this difference happened it needs to explored further in future (case studies). However, this current study suggests researchers to determine the feasibility of a randomized controlled trial.

\section{CONCLUSION}

Deep pressure benefits most children with DCD to a statistically significant degree. The variability in individual children insisted on the need for tailored individual protocol of deep pressure therapy.

\section{ACKNOWLEDGMENTS}

The authors are grateful to the therapist in special school who recorded information about the DCD children.

\section{CONFLICTS OF INTEREST}

The authors declare that they have no competing interest.

\section{FUNDING SOURCE}

Nil/Self.

\section{ETHICAL CLEARANCE}

Obtained from SRM College of Occupational therapy, SRMIST, Kattankulathur.

\section{REFERENCES}

1. Sankar UG, Monisha R. Evaluation of cardio-vascular risk in children with developmental coordination disorder in Indian context-pilot study. Res J Pharm Tech 2018;11:5405-7.

2. Sankar UG, Saritha S. A study of prevalence of developmental coordination disorder (DCD) at Kattankulathur, Chennai. Indian J Physiother Occup Ther 2011;5:63-5.

3. Sankar G, Monisha R. Life impact of developmental coordination disorder: Qualitative analysis of patient and therapist experiences. Biomed Pharmacol J 2019;12:491-4.

4. Shankar UG, Monisha R, Assessment of balance in children with developmental coordination disorder in Indian context. Indian J Public Health Res Dev 2019;10:67-70.

5. American Psychiatric Association. Diagnostic and Statistical Manual of Mental Disorders. $5^{\text {th }}$ ed. Arlington, VA: American Psychiatric Association; 2013.

6. Monisha R, Manikumar M, Krishnakumar A. Evaluating the effectiveness of phonophoresis by piroxicam and dimethyl sulfoxide for women's with osteoarthritis knee joint. Asian J Pharm Clin Res 2018;11:329-31.

7. Senthilselvi R, Boopana M, Sathyan L, Visuvasam P, Ganesan V. Drug utilization pattern in pediatric patients in a secondary care hospital. Int J Pharm Pharm Sci 2019;11:69-74.

8. Thenmozhi P, Priya P. Factors contributing for noncompliance of follow-up care among post cardiac patients. Int J Pharm Pharm Sci 2019;11:22-5

9. Sharma S, Seth N. Optimization of component variables by statistical approach for design of chronotherapeutic dosage form for hypertension. Asian J Pharm Clin Res 2019;12:64-72

10. Johan, Instiaty, Nafrialdi, Purwosunu Y. A prospective survey of appropriateness of pain pharmacotherapy management in post-cesarean section patients in Cipto Mangunkusumo hospital. Int J Appl Pharm 2019;11:280-3

11. McGinnis A, Blakely EQ, Harvey AC, Hodges AC, Rickards JB. The behavioral effects of a procedure used by pediatric occupational therapists. Behav Interv 2013;28:48-57.

12. Stern RA, Arruda JE, Hooper CR, Wolfner GD, Morey CE. Visual analogue mood scales to measure internal mood state in neurologically impaired patients: Description and initial validity evidence. Aphasiology 1997;11:59-71. 